\title{
A LESS INVASIVE APPROACH IN ISTHMIC SPONDYLOLISTHESIS: SPINO-SEMILAMINA-FACET SPARING TECHNIQUE
}

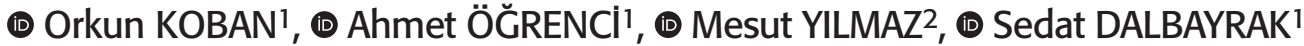 \\ ${ }^{1}$ Okan University Hospital, Clinic of Neurosurgery, İstanbul, Turkey \\ ${ }^{2}$ Neurospinal Academy, Department of Neurosurgery, Istanbul, Turkey
}

Objective: Our study aimed to describe the Spino-Semilamina-Facet Sparing Technique for the surgical treatment of patients with isthmic spondylolisthesis and to present our clinical results.

Materials and Methods: Forty-four patients who were treated with the above-mentioned technique between 2013 and 2015 were retrospectively evaluated. We included patients with grade 1 isthmic listhesis on neutral lumbar X-rays, who usually had a dominant unilateral radicular pain, but did not require discectomy via the approach side. The $12^{\text {th }}$ month low back pain visual analogue scale (VAS) scores, leg pain VAS scores and Oswestry Disability index (ODI) scores were analysed both preoperatively and postoperatively.

Results: The average age of the patients was 46.3 years. Significant improvements were observed in the patients' radicular VAS scores at the approached side 12 months after the surgery $(p<0.0001)$. There were also statistically significant improvements in minor radicular complaints when decompression was performed from the contralateral side compared to when it was done on the approached side ( $<<0.0001)$. Significant improvements were observed when ODI and low back pain VAS scores were compared between the preoperative and postoperative periods $(\mathrm{p}<0.0001, \mathrm{p}<0.0001$, respectively). To date, no additional intervention was applied to any patient.

Conclusion: The technique described in our study provides less invasive principles. The biggest advantages are that there is no need to perform a total laminectomy and the clinical outcomes are favourable.

Keywords: Isthmic spondylolisthesis, less invasive listhesis surgery, spino-semilamina-facet sparing

\section{INTRODUCTION}

Isthmic spondylolisthesis (IS) is one of the most common spinal disorders. It may lead to significant disability, morbidity and loss of the ability to work. The first treatment for IS should always be a conservative medical treatment (medical and physical therapies, injections and corsets), as it will be of some benefit to many patients. However, patients will require surgical treatment, particularly those with persistent back and/ or radicular pain after 6 months of conservative treatment and those with progressive neurological deficits ${ }^{(1,2)}$. The ideal surgical treatment for IS is still controversial. A variety of surgical procedures and approaches have been described, with various grafts and implants used for fusion. Continued efforts are being made to find the optimal surgical modality, determined both radiologically and clinically. Here we present a new surgical technique in IS surgery, namely the SpinoSemilamina-Facet Sparing Technique, encompassing the most widely accepted principles.

\section{MATERIALS AND METHODS}

\section{Study Design}

This study was approved by Okan University Ethics Committee (decision no: 56665618-204.01.07, date: 11.06.2020).

Forty-four patients who were treated with the described technique between 2013 and 2015 were retrospectively evaluated. We included patients who had a dominant unilateral radicular pain, did not require bilateral discectomy or had only chronic lower back pain with grade 1 isthmic listhesis as determined by lumbar magnetic resonance images. The pars defects were bilateral in all the patients, with 38 at the L5S1, one at the L3-4 and five at the L4-5 levels. In the surgical treatment of the patients, interbody cage applications and medial facetectomies were performed on the side of the dominant radicular complaints. The patients who needed discectomy via the medial facetectomy side were excluded in the study. Hence, no patient underwent bilateral discectomy at the level of the listhetic. Besides, there were patients

Address for Correspondence: Orkun Koban, Okan University Hospital, Clinic of Neurosurgery, İstanbul, Turkey

E-mail: drorkunkoban@gmail.com Received: 11.06.2020 Accepted: 29.07.2020

ORCID ID: orcid.org/0000-0002-4721-0502 
who needed decompressions or discectomies at other levels. The contralateral nerve roots in the listhetic segment were decompressed with a contralateral view. In four patients who did not have a similar leg pain or had no radicular pain with chronic lower back pain, the side of the surgery was selected according to the preference of the surgeon.

Clinical outcomes were evaluated by considering the preoperative and postoperative $12^{\text {th }}$ month lower back pain and bilateral leg pain visual analogue scores (VAS). Preoperative and postoperative $12^{\text {th }}$ month Oswestry Disability Index (ODI) scores of the patients were also evaluated.

\section{Surgical Technique}

We preferred to perform stabilisation at the start of the surgery because of the opportunity for disc space distraction to benefit the discectomy and to avoid the unexpected appearance of neurological tissue in the surgical field at the screwing stage. Subsequently, laminofacetectomy was performed, i.e. decompression was initiated at the side where the interbody cage was placed. The spinolaminar junction was broken along the whole lamina by osteotome or cut with the high speed drill on the medial side (Figure 1a). The pars defect was revealed. Circulating fibrous tissue was opened and cleaned by monopolar diathermy or blunt dissection (Figure 1b). Large bone graft (laminofacet) was carefully removed with en-bloc resection. (Figure 1c). A large part of the removed graft (usually facet) was used as an autograft for interbody fusion (Figure 1d1).Autografts can also be resected from large bones in appropriate sizes if the graft is available (Figure 1d2, 3) or from other decompression regions. Unilateral laminofacetectomy was followed by upper root (L5 root for L5-S1 listhesis) decompression through the foramen. (Figure 1e). The well-relaxed spinous process was easily bent to the opposite side with a microdisc retractor and the contralateral nerve roots was easily decompressed (Figure 1e). Bone fragments (lamina) obtained from the large bone graft were placed under the rod between the unstable segment (Figure 1f). Bone fragments obtained from decompressions of the other levels, if any, were placed around the screw heads among the surfaces of the opposite side pars defect and on the preserved interlaminar region at the opposite side (Figure $1 \mathrm{~g})$ for fusion purposes. Listhesis screws can provide reduction at the listhetic vertebra according to the listhesis degree. After distraction and reduction were achieved with the screws, a large autograft (facet; Figure 1d1) obtained from the removed laminofacet was placed in the curetted intervertebral disc space.

\section{Statistical Analysis}

The analyses were performed using the SPSS software (Statistical Package for the Social Sciences, Version 21.0, SSPS Inc., Chicago, IL, USA). Continuous variables were expressed as mean \pm standard deviation and categorical variables were expressed as percentages. Analysis of normality was performed with the Kolmogorov-Smirnov test. Differences in parametric continuous variables for two groups were analysed using the
Independent t-test. Non-parametric continous variables for two groups were analysed using the Mann-Whitney $U$ test. Differences in two different time measures were analysed by repeated measures of analysis of variance. Statistical significance was tested for a level of alpha $=0.05$

\section{RESULTS}

The mean age was 46.3 years (24-68 years). There were 37 female and seven male patients. Mean follow-up period was 26.3 months (18-38 months). The mean Body Mass index was 29.8 .

There were no major complications during the surgical treatment, although two patients had a dural tear and one patient had a superficial wound effusion that did not require additional antibiotic therapy and intervention.

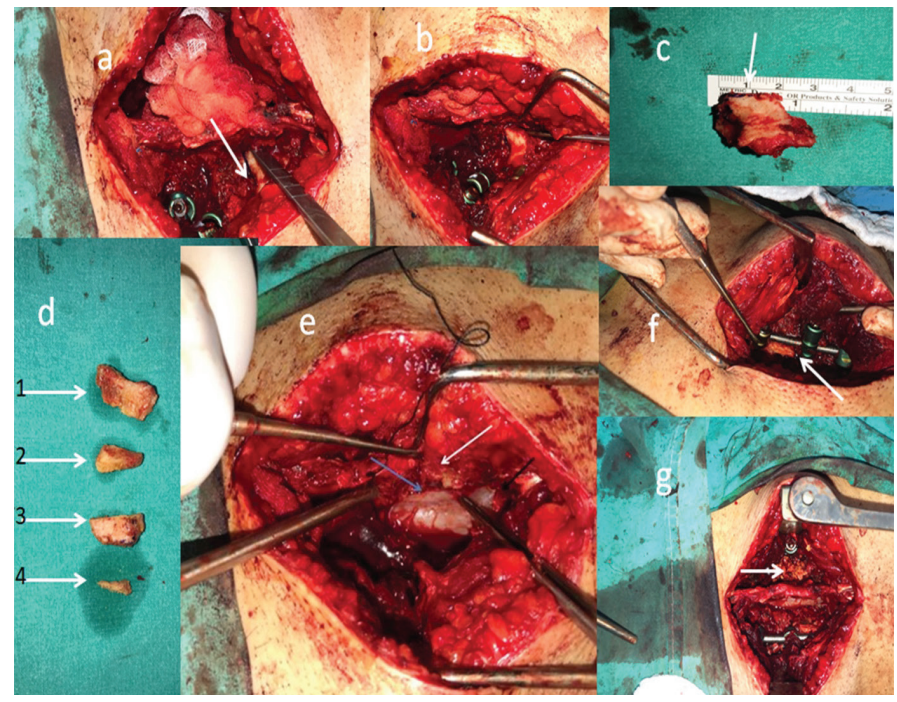

Figure 1. a) Black arrow shows pars defect. Spinolaminar junction is seperated by osteotomy.

b) Appearance before the en-bloc extraction, after seperating from bone junction sites. c) Extracted bone graft. Black arrow shows spinolaminar line seperated with osteotomes. d) 1-The main bone graft (facet) placed in front of the interbody TLIF. 2-Bone graft to be placed around the screw heads or interlaminar area before shredding to the pieces (it can be obtained from laminofacet bone graft if the size of graft is available or from other decompression regions). 3-Graft to be placed under the rod (lamina). 4-Graft to be placed between the faces of the pars defect at the opposite side. (it can be obtained from a laminofacet bone graft if the size of graft is available or from other decompression regions) e) After left laminofacetectomy and excision of soft tissue, we found that the well-relaxed spinous process is easily bended on the opposite side with a microdisc retractor. Blue arrow: Right L5 root, white arrow: spinosus processus, black arrow: right $\mathrm{S} 1$ root f) The placement of a bone graft (Figure 1d3) under the rod between the screws that are placed to the instable segments. g) White arrow: Autograft bone chips obtained from laminofacetectomy (Figure 1d2) and from other decompressions can be applied to the interlaminar area

TLIF: Transforaminal lumbar interbody fusion 
The mean preoperative lower back pain VAS score was $7.86 \pm 1.32$, while the mean postoperative lower back pain VAS score was $2.20 \pm 1.21$. Thus, postoperative back pain was significantly reduced compared with preoperative lower back pain ( $p<0.0001$; Table 1 ). Therefore, surgical treatment was effective in reducing the lower back pain complaints of these patients.

The mean preoperative and postoperative ODIs were $77 \pm 8.93$ and $23.27 \pm 6.42$, respectively. Thus, the mean of the postoperative scores was significantly lower than that of the preoperative scores ( $p<0.0001$; Table 1$)$.

Significant improvements were seen in the leg pain VAS scores on the side where the primary decompression was performed $(p<0.0001$ in each group; Table 2). Additionally, significant improvements were seen in the contralateral leg pain VAS scores, although contralateral decompression was performed ( $p<0.0001$ in each group; Table 2$)$. These results showed that the contralateral decompression in IS was effective in terms of pain control.

We also examined whether the improvement of the contralateral and ipsilateral leg pain differed according to the location of the defect and found no significant difference between the two (Table 3).
We also compared the mean of the difference in lower back VAS and ODI scores between the preoperative and postoperative periods in term of the location of defect (Table 3).

Regarding lower back pain VAS scores, the mean preoperativepostoperative difference in L4-5 + L3-4 and L5-S1 patients was $6.16 \pm 2.13$ and $5.57 \pm 1.81$, respectively. This difference was not statistically significant (Table 3). Regarding ODI scores, the mean preoperative-postoperative difference in L4-5 or L3-4 and L5-S1 patients was 53.50 \pm 9.58 and 53.763 \pm 10.276 , respectively. This calculated difference was not statistically significant (Table 3).

Considering these analyses, we can deduce that our technique led to a significant improvement in both the lower back and bilateral leg pain VAS scores and ODI scores independently from the location of the defect.

No additional intervention or revision surgery was performed to any patient till date. Fusion rates were assessed with lumbar computed tomography (CT), and fusion was observed in 38 (86.3\%) patients.

\section{Illustrative Case 1}

A 24-year-old male patient was admitted to our clinic with bilateral leg pain (Dominant on the left side), which began 3 years ago, but became more severe in the last 8 weeks.

Table 1. The comparisons of visual analogue scale and Oswestry Disability index values between the preoperative and postoperative periods

\begin{tabular}{|c|c|c|c|}
\hline & Mean & SD & $\mathbf{p}$ \\
\hline Preoperative right leg pain VAS score & 5.54 & 3.15 & \multirow{2}{*}{$<0.0001$} \\
\hline Postoperative right leg pain VAS score & 1.31 & 1.11 & \\
\hline Preoperative left leg pain VAS score & 4.45 & 2.88 & \multirow{2}{*}{$<0.0001$} \\
\hline Postoperative left leg pain VAS score & 1.15 & 1.01 & \\
\hline Preoperative low back pain VAS score & 7.86 & 1.32 & $<0.0001$ \\
\hline Preoperative ODI score & 77.00 & 8.93 & \multirow{2}{*}{$<0.0001$} \\
\hline Postoperative ODI score & 23.27 & 6.42 & \\
\hline
\end{tabular}

VAS: Visual analogue scale, ODI: Oswestry disability index, SD: Standard deviation

Table 2. The comprasions of the legs pain according to the side of the surgery

\begin{tabular}{|llll}
\hline & & Mean & SD \\
\hline \multirow{2}{*}{ Side of surgery = Left } & Preoperative right leg pain VAS score & 2.45 & 1.63 \\
\cline { 2 - 4 } & Postoperative right leg pain VAS score & 0.60 & 0.68 \\
\hline \multirow{2}{*}{ Side of surgery = Left } & Preoperative left leg pain VAS score & 7.15 & 1.53 \\
\cline { 2 - 4 } Side of surgery = Right & Postoperative left leg pain VAS score & 1.65 & 1.08 \\
\hline \multirow{2}{*}{ Side of surgery = Right } & Preoperative right leg pain VAS score & 8.12 & 1.07 \\
\cline { 2 - 4 } & Postoperative right leg pain VAS score & 1.91 & 1.06 \\
\hline & Preoperative left leg pain VAS score & 2.20 & 0.0001 \\
\cline { 2 - 4 } & Postoperative left leg pain VAS score & 0.75 & 0.73 \\
\hline
\end{tabular}

VAS: Visual analogue scale, ODI: Oswestry disability index, SD: Standard deviation 
Table 3. The comparisons of the improvement differences between preoperative and postoperative periods according to the location of defect

\begin{tabular}{|c|c|c|c|c|c|}
\hline \multicolumn{6}{|l|}{ Group statistics } \\
\hline Location of defect & & $\mathbf{N}$ & Mean & SD & $\mathrm{p}$ \\
\hline \multirow{3}{*}{$\begin{array}{l}\text { Difference between preoperative-postoperative contralateral leg } \\
\text { pain VAS score }\end{array}$} & $L 4-5$ or $L 3-4$ & 6 & 3.50 & 2.16 & \multirow{3}{*}{ NS } \\
\hline & & & & & \\
\hline & L5-S1 & 38 & 3.44 & 2.91 & \\
\hline \multirow{2}{*}{$\begin{array}{l}\text { Difference between preoperative-postoperative ipsilateral leg } \\
\text { pain VAS }\end{array}$} & $\mathrm{L} 4-5$ or L3-4 & 6 & 3.50 & 2.34 & \multirow[b]{2}{*}{ NS } \\
\hline & L5-S1 & 38 & 4.15 & 2.33 & \\
\hline \multirow{3}{*}{ Difference between preoperative-postoperative lowback pain } & $L 4-5$ or $L 3-4$ & 6 & 6.16 & 2.13 & \multirow{3}{*}{ NS } \\
\hline & & & & & \\
\hline & L5-S1 & 38 & 5.57 & 1.81 & \\
\hline \multirow{3}{*}{ Difference between preoperative-postoperative ODI score } & $L 4-5$ or $L 3-4$ & 6 & 53.50 & 9.58 & \multirow{3}{*}{ NS } \\
\hline & & & & & \\
\hline & L5-S1 & 38 & 53.76 & 10.27 & \\
\hline
\end{tabular}

Dorsiflexion weakness was present in the left foot of the patient $(4 / 5)$. The patient's preoperative lower back pain VAS score was 9 , right leg pain VAS score was 3 , left leg pain VAS score was 9 and ODI score was $80 \%$. L5-S1 bilateral pars interarticularis defect and L4-5 and L5-S1 left paracentral disc herniation were present on radiological examination. The patient was operated upon according to the technique that we have described earlier (Figure 1a, b, c, d, e, f, g). Postoperative early-stage CT is shown in Figure 2 a, b, c, d, e and f. No complications occurred and

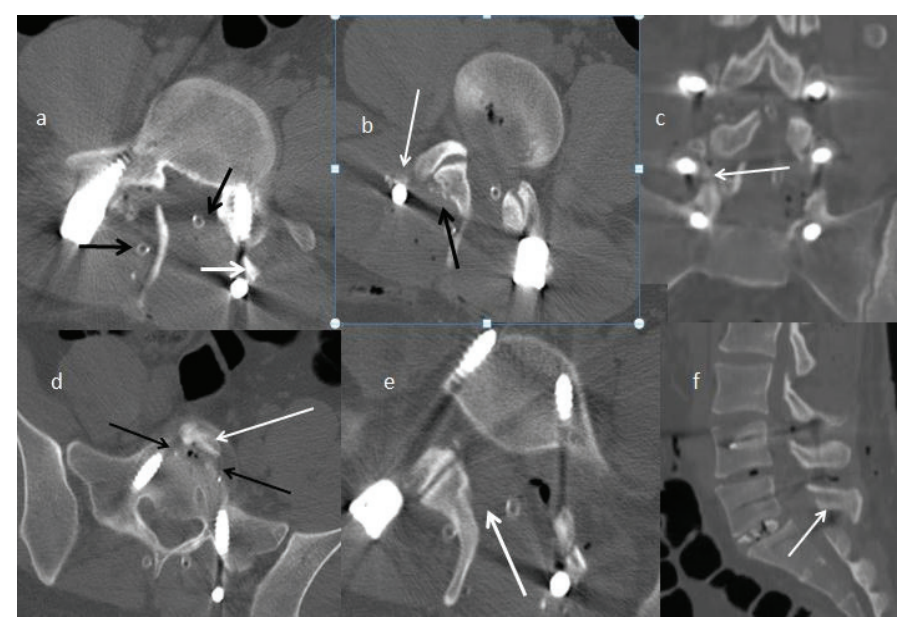

Figure 2. a) White arrow: Bone graft (lamina) placed under rod. Black arrows: Hemovac drains.

b) White arrow: Bone grafts around the screw heads. Black arrow: Bone grafts applied to the interlaminar region. c) White arrow: Autograft placement between the faces of the pars defects at the opposite side. d) White arrow: Large piece of autograft (facet) in front of the cage at the disc space. Black arrows: the landmarks of the TLIF cage e) White arrow: The route of bilateral decompression from the unilateral approach. f) Sagittal view in the postoperative course. White arrow: Preserved L5 spinosus processus TLIF: Transforaminal lumbar interbody fusion the patient was discharged on the third postoperative day. The patient's postoperative $12^{\text {th }}$ month lower back pain VAS score was 2, right leg pain VAS score was 0 , left leg pain VAS score was 0 and ODI score was $24 \%$.

\section{Illustrative Case 2}

A 48-year-old female patient was admitted to our clinic with bilateral leg pain dominant on the right side, and severe lower back pain for the past 2 years. She had not benefited from conservative treatments and had no motor weakness. The patient's preoperative lower back pain VAS score was 8 , right leg pain VAS score was 8 , left leg pain VAS score was 4 and ODI score was $76 \%$. L3-4 bilateral pars interarticularis defect and L3-4 right paracentral foraminal disc herniation were present on the radiological examination. The patient was operated according to our technique and the postoperative CT is shown in Figure 3. No complication occurred and the patient was discharged on the third postoperative day. The patient's

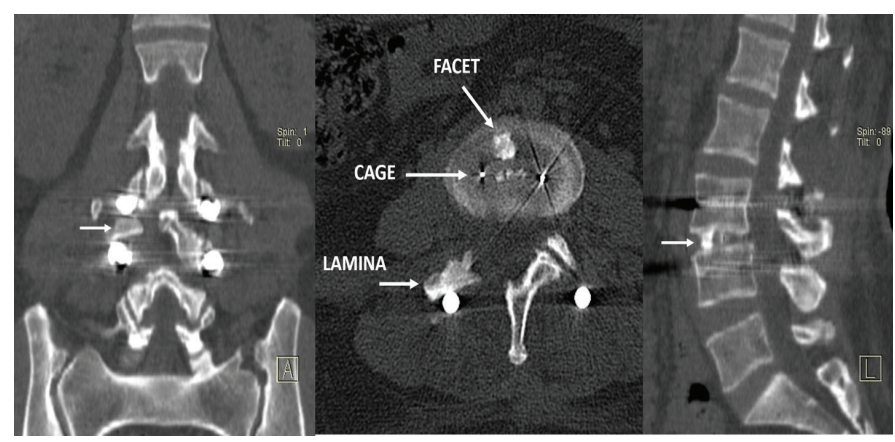

Figure 3. White arrow in the coronal section of L3-4 short segment stabilised patient shows the lamina originated bone graft placed under the rod; white arrow in the sagittal section shows the facet orginated interbody graft. Axial section demonstrates that the surgical treatment is performed with a one side laminofacet sparing 
postoperative $12^{\text {th }}$ month lower back pain VAS score was 2, right leg pain VAS score 1, left leg pain VAS score 1 and ODI score $16 \%$.

\section{DISCUSSION}

IS is a spinal disorder that can be seen in young and adult age groups, often involving L5-S1 and L4-5 defects, affecting up to $8 \%$ of the general population ${ }^{(1,2)}$. It is defined as the forward slippage of a vertebra due to a defect in the pars interarticularis. Medical, conservative and physical therapymaybe recommended to patients with $\mathrm{IS}^{(3-5)}$. Surgical options range from simple decompression to stabilisation with or without fusion ${ }^{(1,6-10)}$. Decompression alone is no longer recommended ${ }^{(11,12)}$.

Many authors have developed many surgical techniques to treat IS by providing stability via fusion. These surgical options include posterolateral intertransverse process fusion; Buck direct repair, facet joint screws; and transforaminal lumbar interbody fusion (TLIF), anterior Lumbar Interbody Fusion (ALIF) and posterior lumbar interbody fusion (PLIF) applications with or without combined anterior and posterior fusion ${ }^{(13-17)}$. Fusion surgery with decompression has become the primary treatment because patients undergoing fusion surgery can be controlled for pain by stabilising the unstable segments. When we looked at the outcomes of the patients who underwent fusion surgery, the preoperative lower back pain VAS and ODI scores of the patients showed a significant improvement in the postoperative period.

Until now, various surgical approaches and different comparisons have been reported in many articles. The width of the fusion area is important in fusion surgery(3). Posterolateral fusion is very common in transpedicular fixation. Interbody fusion in IS surgery is usually meaningful for success in fusion, but fusion between the laminae will expand the field of fusion and serve the main purpose of this surgery ${ }^{(18,19)}$. This protected interlaminar space can be used for posterior fusion because of the bone grafts. Mobile or semi-mobile lamina is not necessarily involved in the stabilisation effort, but will increase the chances of success. Previously, laminoplasty had been applied to IS, and Kotil(20) reported the 5-year follow-up outcomes and stated that the results were excellent. However, it is also possible to protect the lamina without its removal and without performing laminoplasty. We can protect one side of the lamina with unilateral laminofacetectomy. The bone graft repair was first described by Kimura in $1968^{(21)}$. To date, direct repair-related studies and their positive outcomes and the follow-up outcomes have been published ${ }^{(22-24)}$. In the practice of spinal fusion surgery in IS, the procedure using the bone graft that is placed into the pars defect was not preferred frequently, but it would be logical to use it to expand the field of the fusion area.

Posterolateral fusion is still the most commonly used fusion strategies in instabilities. Some publications show that there is no significant difference between posterolateral fusion and interbody fusion, a large number of authors have indicated that posterolateral and interbody fusions give excellent results when used together ${ }^{(25,26)}$. We tried to achieve a posterolateral fusion with a single bone graft placed under the rod between the unstable segments. Placing a single piece of bone graft under the rod also prevents the graft from being lost in the paravertebral muscles.

There are numerous articles about the use of interbody grafts. Allografts cannot provide enough support to be used as interbody grafts, whereas high fusion rates have been reported for autografts. Even $100 \%$ fusion rates were reported in certain studies that used cages combined with iliac wing and/or spinous process autografts ${ }^{(27-29)}$. The use of the interbody cage also increases the fusion success. It is shown that the interbody cage with autogenous bone grafting and pedicle screw fixation are more useful in adult spondylolisthesis for improving the fusion rate and preventing long-term instabilities, compared with the simple cage alone with pedicle screw fixation ${ }^{(30)}$. The iliac wing is frequently used as an autograft, but this increases both patient morbidity and the source of pain and infection. It often requires an additional incision ${ }^{(31-33)}$. Positive radiological and clinical outcomes were reported in a study in which a single piece of spinolaminar process was used as an autograft ${ }^{(12)}$. We used the large piece of the inferior articular face of the facet joint as an interbody graft, which is already separated from the large bone graft (laminofacet). We partially performed decortication and prepared it as one tricortical large piece of autograft.

Decompression plays an important role in IS surgery and neurosurgery. Decompression is frequently performed in spinal disorders using minimally invasive techniques and less bone removal. The aim of minimally invasive spinal surgery is to achieve the same purposes as the other open surgical techniques via a less traumatic approach ${ }^{(34)}$. Bilateral decompression from one side is one of the commonly used minimally invasive techniques. To date, numerous articles about bilateral decompression from one side have been written(35-37). Additionally, it has been described that these approaches achieved very important clinical outcomes for the contralateral side symptoms ${ }^{(38,39)}$. Bilateral decompression via the unilateral approach was not defined in IS surgery to date. After a one-sided laminofacetectomy, the preserved spinolaminar bone, which is already easy to mobilise, is partly tilted, and the patient is partially rotated to the opposite side and microscopical decompression can be achieved for the contraletaral side (flavectomy + foraminotomy). Up to four nerve roots can be decompressed with such a minimal approach (i.e. L5, S1 bilateral nerve roots for L5-S1 listhesis). Indeed, we found a significant improvement in postoperative ipsilateral and contralateral leg pains. Ipsilateral and contralateral leg pains were also compared according to the side where the decompression was applied and significant improvements were seen. On the other hand, according to the analysis of 
the location, a significant improvement was observed in the ipsilateral and contralateral leg pain. In other words, even if the location changes, contralateral decompression can provide significant improvement in these patients.

Decompression is provided without removing or cutting the posterior tension band in this surgery. This also helps in suturing the fascia tightly at the mid-line, in the closure phase at the end of the surgery. This also ensures that no dead space is left in the surgical area that can give rise to infections and subcutaneous collections ${ }^{(40)}$. Preserving the posterior tension band and not applying total laminectomy as a less invasive approach decreases the dead space and complications in the surgical field(41). No epidural hematoma, subcutaneous collection, sub-fascial collection or infection was seen in our patients.

We applied the interbody cage, which is almost always recommended to be performed in IS surgeries. After the facetectomy on one side, it was possible to apply the TLIF cage in the interbody space and enlarge the fusion area, in order to maintain the foraminal distraction and disc height ${ }^{(42)}$. Although there were no significant differences between the TLIF and PLIF in terms of surgical outcomes in the literature, recommending the use of TLIF is more intense ${ }^{(43-45)}$. We also used Banana TLIF for bilateral and anterior support from one side. Providing anterior support further increases the chance of fusion ${ }^{(30,46,47)}$. Beside these, we avoided additional cost (avoiding allograft use) by using autografts. We did not perform any extra incision to the patient for autograft. Extra incision for autograft also increases the duration of hospital stay and treatment $\operatorname{cost}^{(48,49)}$. Consequently, we did not apply a revision surgery to any of the patients that we operated using this technique. Significant improvement in lower back pain VAS, leg VAS and ODI scores were observed in all the patients.

\section{Study Limitations}

This study has some limitations. The follow-up period was short. In addition, no comparison was made with patients operated using the standard surgical techniques. Besides this, variables such as comorbidity and risk factors in the sample group of these patients were not included in the study.

\section{CONCLUSION}

With this surgical technique, it is possible to perform bilateral decompression from one side and to maintain the interlaminar space in order to keep the fusion area wider, to preserve the posterior tension band, and to perform interbody fusion with a one-piece large autograft obtained from a one-sided facetectomy. Hence, we believe our technique can be described as the spino-semilamina-facet sparing approach in IS.

\section{Ethics}

Ethics Committee Approval: This study was approved by Okan University Ethics Committee (decision no: 56665618-204.01.07, date: 11.06 .2020$)$.
Informed Consent: The informed consents received.

Peer-review: Externally and internally peer-reviewed.

\section{Authorship Contributions}

Concept: O.K., A.Ö., S.D., Design: O.K., A.Ö., Data Collection or Processing: O.K., M.Y., S.D., Analysis or Interpretation: O.K., A.Ö., S.D., Literature Search: O.K., A.Ö., Writing: O.K., A.Ö., S.D.

Conflict of Interest: No conflict of interest was declared by the authors.

Financial Disclosure: The authors declared that this study received no financial support.

\section{REFERENCES}

1. Molinari RW. Adult isthmic spondylolisthesis. Curr Opin Orthop. 2002;13:178-83.

2. Kalichman L, Kim DH, Li L, Guermazi A, Berkin V, Hunter DJ. Spondylolysis and spondylolisthesis: Prevalence and association with low back pain in the adult community-based population. Spine (Phila Pa 1976). 2009;34:199-205.

3. Audat ZM, Darwish FT, Al Barbarawi MM, Obaidat MM, Haddad $\mathrm{WH}$, Bashaireh KM, et al. Surgical management of low grade isthmic spondylolisthesis; a randomized controlled study of the surgical fixation with and without reduction. Scoliosis. 2011;6:14.

4. Klein G, Mehlman CT, McCarty M. Nonoperative treatment of spondylolysis and grade I spondylolisthesis in children and young adults: a meta-analysis of observational studies. J Pediatr Orthop. 2009;29:146-56.

5. Bradford DS. Management of spondylolysis and spondylolisthesis. Instr Course Lect. 1983;32:151-62.

6. Lane WA. Case of spondylolisthesis with progressive paraplegia after laminectomy. Lancet. 1893;1:991.

7. Vibert BT, Sliva ChD, Herkowitz HN. Treatment of instability and spondylolisthesis. Surgical versus nonsurgical treatment. Clin Orthop Relat Res. 2006;443:222-7.

8. Jacobs WCA, Veerling A, De Kleuver M. Fusion for low-grade adult isthmic spondylolisthesis: a sysmatic review of the literature. Eur Spine J. 2006;15:391-402.

9. Suk SI, Lee CK, Kim WJ, Lee JH, Cho KJ, Kim HG. Adding posterior lumbar interbody fusion to pedicle screw fixation and posterolateral fusion after decompression in spondylolytic spondylolisthesis. Spine J. 1997;22:210-9.

10. Buck JE. Direct repair of the defect in spondylolisthesis. Preliminary report. J Bone Joint Surg Br. 1970;52:432-7.

11. Shufflebarger HL, Geck MJ. High-grade isthmic dysplastic spondylolisthesis: Monosegmental surgical treatment. Spine. 2005;6:42-8

12. Yilmaz T, Dalbayrak S, Yaman O, Yilmaz M, Ayten M, Turan $Y$, et al A modified technique for the treatment of isthmic spondylolisthesis. Turk Neurosurg. 2015;25:394-403.

13. Baek OK, Lee SH. Extraforaminal lumbar interbody fusion for the treatment of isthmic spondylolisthesis. J Spinal Disord Tech. 2009;22:219-27.

14. Gerszten PC, Tobler W, Raley TJ, Miller LE, Block JE, Nasca RJ. Axial presacral lumbar interbody fusion and percutaneous posterior fixation for stabilization of lumbosacral isthmic spondylolisthesis. J Spinal Disord Tech. 2012;25:36-40.

15. Gong K, Wang Z, Luo Z. Reduction and transforaminal lumbar interbody fusion with posterior fixation versus transsacral cage fusion in situ with posterior fixation in the treatment of Grade 2 adult isthmic spondylolisthesis in the lumbosacral spine. J Neurosurg Spine. 2010;13:394-400.

16. Hackenberg L, Halm H, Bullmann V, Vieth V, Schneider M, Liljenqvist U. Transforaminal lumbar interbody fusion: A safe technique with satisfactory three to five year results. Eur Spine J. 2005;14:551-8. 
17. Sears W. Posterior lumbar interbody fusion for lytic spondylolisthesis: Restoration of sagittal balance using insert-and-rotate interbody spacers. Spine J. 2005;5:161-9.

18. Ge CM, Wang YR, Jiang SD, Jiang LS. Thoracolumbar burst fractures with a neurological deficit treated with posterior decompression and interlaminar fusion. Eur Spine J. 2011;20:2195-201.

19. Knop C, Sitte I, Canto F, Reinhold M, Blauth M. Successful posterior interlaminar fusion at the thoracic spine by sole use of $\beta$-tricalcium phosphate. Arch Orthop Trauma Surg. 2006;126:204-10.

20. Kotil K. Replacement of Vertebral Lamina (Laminoplasty) in Surgery for Lumbar Isthmic Spondylolisthesis: 5-Year Follow-Up Results. Asian Spine J. 2016;10:443-9.

21. Kimura M. My method of filing the lesion with spongy bone in spondylolysis and spondylolistesis Seikei Geka. 1968;19:285-96.

22. Askar Z, Wardlaw D, Koti M. Scott wiring for direct repair of lumbar spondylolysis. Spine (Phila Pa 1976). 2003;28:354-57.

23. Dai LY, Jia LS, Yuan W, Ni B, Zhu HB. Direct repair of defect in lumbar spondylolysis and mild isthmic spondylolisthesis by bone grafting, with or without facet joint fusion. Eur Spine J. 2001;10:78-83.

24. Gillet P, Petit M. Direct repair of spondylolysis without spondylolisthesis, using a rod-screw construct and bone grafting of the pars defect. Spine. 1999;24:1252-6.

25. McAnany SI, Baird EO, Qureshi SA, Hecht AC, Heller JG, Anderson PA. Posterolateral fusion versus interbody fusion for degenerative spondylolisthesis: a systematic review and meta-analysis. Spine. 2016;41:1408-14

26. Macki M, Bydon M, Weingart R, Sciubba D, Wolinsky JP, Gokaslan ZL, et al. Posterolateral fusion with interbody for lumbar spondylolisthesis is associated with less repeat surgery than posterolateral fusion alone. Clin Neurol Neurosurg. 2015;138:117-23.

27. Jorgenson SS, Lowe TG, France J, Sabin J. A Prospective Analysis of Autograft Versus Allograft in Posterolateral Lumbar Fusion in the Same Patient: A Minimum of 1-Year Follow-up in 144 Patients. Spine. 1994; 19:2048-52

28. Müslüman AM, Yilmaz A, Cansever T, Cavuşoğlu H, Colak I, Genç $\mathrm{HA}$, et al. Posterior lumbar interbody fusion versus posterolateral fusion with instrumentation in the treatment of low-grade isthmic spondylolisthesis: Midterm clinical outcomes. I Neurosurg Spine. 2011; 14:488-96.

29. Suk SI, Lee CK, Kim WJ, Lee JH, Cho KJ, Kim HG. Adding posterior lumbar interbody fusion to pedicle screw fixation and posterolateral fusion after decompression in spondylolytic spondylolisthesis. Spine (Phila Pa 1976). 1997;22:210-9.

30. Dou Y, Hao D, Wen S, He B. Comparison of clinical outcomes between two methods of posterior lumbar interbody fusion in adult spondylolisthesis. Zhongguo Xiu Fu Chong Jian Wai Ke Za Zhi. 2006;20:743-6.

31. Almaiman M, Al-Bargi HH, Manson P. Complication of anterior iliac bone graft harvesting in 372 adult patients from May 2006 to May 2011 and a literature review. Craniomaxillofacial Trauma and Reconstruction. 2013;6:257-66.

32. Sasso RC, LeHuec JC, Shaffrey C. Spine Interbody Research Group. lliac crest bone graft donor site pain after anterior lumbar interbody fusion: a prospective patient satisfaction outcome assessment. Clin Spine Surg. 2005;18:77-81.

33. Zenner J, Hitzl W, Mayer M, Koller H. Analysis of postoperative pain at the anterior iliac crest harvest site: a prospective study of the intraoperative local administration of ropivacaine. Asian Spine Journal. 2015;9:39-46.

34. Wang J, Zhou Y, Zhang ZF, Li CQ, Zheng W], Liu J. Comparison of onelevel minimally invasive and open transforaminal lumbar interbody fusion in degenerative and isthmic spondylolisthesis grades 1 and 2 . Eur Spine J. 2010;19:1780-4.

35. Palmer S, Turner, R, Palmer R. Bilateral decompression of lumbar spinal stenosis involving a unilateral approach with microscope and tubular retractor system. Journal of Neurosurgery: Spine. 2002;97:213-7.

36. Sasai K, Umeda M, Maruyama T, Wakabayashi E, lida H. Microsurgical bilateral decompression via a unilateral approach for lumbar spinal canal stenosis including degenerative spondylolisthesis. Journal of Neurosurgery: Spine. 2008;9:554-9.

37. Spetzger $U$, Bertalanffy $H$, Reinges MT, Gilsbach JM. Unilateral laminotomy for bilateral decompression of lumbar spinal stenosis part II: Clinical experiences. Acta neurochirurgica. 1997;139:397-403.

38. Öğrenci A, Koban O, Yaman O, Yilmaz M, Dalbayrak S. Clinical Comparison Between Patients Operated for Unilateral Radiculopathy via a Contralateral (Facet-Sparing) and Ipsilateral Side Approach. Turk Neurosurg. 2018;28:610-5.

39. Çavuşoğlu H, Kaya RA, Türkmenoglu ON, Tuncer C, Colak I, Aydin Y. Midterm outcome after unilateral approach for bilateral decompression of lumbar spinal stenosis: 5-year prospective study. Eur Spine J. 2007; 16:2133-42.

40. Alexander JW, Solomkin JS, Edwards MJ. Updated recommendations for control of surgical site infections. Annals of Surg. 2011;253:1082-93.

41. Quaile A. Infections associated with spinal implants. Int orthop. 2012;36:451-6.

42. Dennis S, Watkins R, Landaker S, Dillin W, Springer D. Comparison of disc space heights after anterior lumbar interbody fusion. Spine. 1989;14:876-8.

43. Kim E, Chotai, S, Stonko D, Wick J, Sielatycki A, Devin CJ. A retrospective review comparing two-year patient-reported outcomes, costs, and healthcare resource utilization for TLIF vs. PLF for singlelevel degenerative spondylolisthesis. Eur Spine J. 2017;1-9.

44. Asil K, Yaldiz C. Retrospective Comparison of Radiological and Clinical Outcomes of PLIF and TLIF Techniques in Patients Who Underwent Lumbar Spinal Posterior Stabilization. Medicine. 2016;95:17.

45. Humphreys SC, Hodges SD, Patwardhan AG, Eck JC, Murphy RB, Covington LA. Comparison of posterior and transforaminal approaches to lumbar interbody fusion. Spine. 2001;26:567-71.

46. Greenough CG, Peterson MD, Hadlow S, Fraser RD. Instrumented posterolateral lumbar fusion: results and comparison with anterior interbody fusion. Spine. 1998;23:479-86.

47. Cole CD, McCall TD, Schmidt MH, Dailey AT. Comparison of low back fusion techniques: transforaminal lumbar interbody fusion (TLIF) or posterior lumbar interbody fusion (PLIF) approaches. Curr Rev Musculoskelet Med. 2009;2:118-26.

48. Banwart JC, Asher MA, Hassanein RS. Iliac crest bone graft harvest donor site morbidity. A statistical evaluation. Spine (Phila Pa 1976). 1995;20:1055-60.

49. Kho VKS, Chen WC. Posterolateral fusion using laminectomy bone chips in the treatment of lumbar spondylolisthesis. International Orthopaedics. 2008;32:115-9. 